\title{
Evaluation of a mosquito home system for controlling Aedes aegypti
}

\author{
Ahmad Mohiddin Mohd Ngesom', Anis Ahmad Razi', Nur Syahirah Azizan', Nazni Wasi Ahmad², \\ Asmalia Md Lasim³ ${ }^{3}$ Yanfeng Liang ${ }^{4}$, David Greenhalgh ${ }^{4}$, Jasmine Chia Siew Min ${ }^{5}$, Mazrura Sahani ${ }^{1}$, \\ Rozita $\mathrm{Hod}^{6}$ and Hidayatulfathi Othman ${ }^{1 *}$
}

\begin{abstract}
Background: Dengue is a significant public health issue that is caused by Aedes spp. mosquitoes. The current vector control methods are unable to effectively reduce Aedes populations and thus fail to decrease dengue transmission. Hence, there is an urgent need for new tools and strategies to reduce dengue transmission in a wide range of settings. In this study, the Mosquito Home System (MHS) and Mosquito Home Aqua (MHAQ) formulations were assessed as commercial autodissemination traps in laboratory and small-scale field trials.

Method: Multiple series of laboratory and small-scale field trials were performed to assess the efficacy of MHS and MHAQ exposed to Ae. aegypti. In the laboratory trials, various parameters such as fecundity, fertility, wing size, oviposition preferences, residual effects, and MHAQ transference to other containers through controlled experiments were tested. For small-scale field trials, the efficacy of the MHS and MHAQ approaches was determined to ascertain whether wild mosquitoes could transfer the MHAQ formulation from MHS stations to ovitraps.
\end{abstract}

Results: The data revealed that Ae. aegypti was highly susceptible to low concentrations of MHAQ formulations and had a residual effect of up to 3 months, with $\mathrm{MHAQ}$ exposure affecting fecundity, fertility, and mosquito wing size. In the oviposition studies, gravid females strongly preferred the hay infusion compared to tap water and MHAQ during egg-laying in the laboratory. Nevertheless, the use of commercial MHAQ by MHS was highly attractive in field settings compared to conventional ovitraps among local Aedes spp. mosquitoes. In addition, MHAQ horizontal transfer activities in the laboratory and small-scale field trials were demonstrated through larval bioassays. These findings demonstrated the potential of MHAQ to be transferred to new containers in each study site.

Conclusion: This study provided proof of principle for the autodissemination of MHAQ. Through further refinement, this technique and device could become an effective oviposition trap and offer an alternative preventive tool for vector control management.

Keywords: Autodissemination, Horizontal transfer, Inhibition emergences, Insect growth regulators, Vector control management

\footnotetext{
*Correspondence: hida@ukm.edu.my

${ }^{1}$ Center for Toxicology and Health Risk, Faculty of Health Sciences,

Universiti Kebangsaan Malaysia, 50300 Kuala Lumpur, Federal Territory of Kuala Lumpur, Malaysia

Full list of author information is available at the end of the article
} original author(s) and the source, provide a link to the Creative Commons licence, and indicate if changes were made. The images or other third party material in this article are included in the article's Creative Commons licence, unless indicated otherwise in a credit line to the material. If material is not included in the article's Creative Commons licence and your intended use is not permitted by statutory regulation or exceeds the permitted use, you will need to obtain permission directly from the copyright holder. To view a copy of this licence, visit http://creativecommons.org/licenses/by/4.0/. The Creative Commons Public Domain Dedication waiver (http://creativeco mmons.org/publicdomain/zero/1.0/) applies to the data made available in this article, unless otherwise stated in a credit line to the data. 


\section{Background}

Aedes aegypti and Aedes albopictus are both primary dengue vectors found in Malaysia [1], which ranks third in the number of dengue cases reported among countries in the Western Pacific Region [2]. Dengue can be transmitted through the bites of female Aedes spp. mosquitoes, with Ae. aegypti and Ae. albopictus most efficiently adapted to human dwelling areas with artificial container habitats that have a large amount of food.

Although the first licensed dengue vaccine named Dengvaxia was developed against all dengue serotypes [3], the implementation of Dengvaxia was limited to subnational public health programs in Brazil and the Philippines [4]. It offers limited efficacy and can increase the severity of dengue, especially against serotypes 1 and $2[5,6]$. Therefore, the best prevention strategy is to control the populations of Aedes mosquitoes and minimize the presence of mosquitoes [7, 8].

The control measures against Aedes spp. populations are based on the recommendations of the World Health Organization (WHO), including implementing source reduction strategies, larvicides, biological controls, lethal oviposition trap, and insecticides, which are used intensively during dengue outbreaks. In Malaysia, thermal fogging and ultra-low volume sprays are the primary interventions when dengue cases are reported [9]. However, uncontrolled use of insecticides during epidemics resulted in increased resistance among mosquitoes to major pesticide classes such as pyrethroids, organophosphates, and carbamate classes [10-13].

Pyriproxyfen is a broad-spectrum insect growth regulator that inhibits the emergence of mosquitoes [14] and is categorized as an eco-friendly pesticide, whereby its application does not remain in water and soil, and its biological degradation cycle serves as a carbon source for other microorganisms $[15,16]$. In addition, pyriproxyfen has also been approved for use in drinking water at the recommended application rate [17]. Pyriproxyfen possesses an unexploited potential as a larvicide against mosquitoes, with the autodissemination of pyriproxyfen being suggested by researchers as a novel form of vector control [18-20].

Autodissemination is a very promising and attractive concept that exploits the behavior of female mosquitoes to transfer small particles of insecticides to other cryptic sites [21] and thus prevents the emergence of immature larvae [22]. This was initially demonstrated in the laboratory [23] and subsequently validated by other researchers [24]. Recently, Abad-Franch et al. discovered that mosquitoes could efficiently transfer pyriproxyfen to artificial sites with $100 \%$ coverage of dwelling sites within 50 ha, which generated more than a ten-fold increase in pupal mortality and, as a result, led to a decrease in adult emergence [25]. Studies using autodissemination techniques conducted in Manacapuru, a city in Brazil with 60,000 inhabitants, have shown a reduction in the Ae. aegypti and Culex spp. populations [26]. Further research demonstrated that female mosquitoes could be contaminated, leading to the transfer of pyriproxyfen to other oviposition sites and significantly inhibited adult emergence in laboratory settings and under field conditions [18].

The Mosquito Home System (MHS) is the first commercial trap in Malaysia to adopt the autodissemination concept using the Mosquito Home Aqua (MHAQ) solution. The trap is made of inexpensive polyethylene and operates without electricity or any additional extensions. Its design is based on a gravity-fed watering system that effectively dispenses a trap solution for up to 2 months. Female mosquitoes are exposed to the solution inside the traps by tarsal contact during oviposition, and the insecticide is transferred to other oviposition sites. Over the years, several studies have been performed on MHS and MHAQ and have yielded promising results, although they have been poorly documented [27]. Thus, this study aimed to investigate the efficacy of autodissemination approaches against Ae. aegypti in laboratory settings using the MHS devices and MHAQ formulations. In small-scale field evaluations, the efficacy of the MHS and MHAQ approaches were evaluated to ascertain whether wild mosquitoes were able to transfer the MHAQ formulation from MHS stations to the ovitraps. It was anticipated that MHS and MHAQ may have a significant impact on Ae. aegypti and potentially emerge as a vector control tool.

\section{Methods}

\section{Mosquitoes}

A susceptible strain of Ae. aegypti known as the Institute for Medical Research IMR strain, which originated in Selangor, was used in all experiments in this study and was free from any insecticide exposure. It was maintained in colonies for more than F1000 generations in the insectarium of IMR, Kuala Lumpur. The mosquitoes were reared in the Laboratory of Medical Entomology, Universiti Kebangsaan Malaysia at $26 \pm 4{ }^{\circ} \mathrm{C}$ and $60 \pm 20 \%$ relative humidity (RH). Larvae were fed TetraMin ${ }^{\circledR}$ fish food, and cotton soaked with $10 \%$ sucrose was fed to adult mosquitoes as nourishment. Female mosquitoes obtained from the $\mathrm{F}_{0}$ generation fed on guinea pig (Cavia porcellus) blood, and their $F_{1}$ and $F_{2}$ progenies were used in the present study.

\section{Pyriproxyfen}

MHAQ is a commercial solution containing $0.004 \%$ pyriproxyfen and is used in conjunction with the MHS 
device (One Team Networks, Sdn. Bhd., Malaysia). Full information about the formulation cannot be disclosed as it is a trade secret of the company.

\section{Mosquito Home System as autodissemination station} The MHS trap (Fig. 1) is a cylinder-shaped black polyethylene container that is $19.7 \mathrm{~cm}$ high and $14.6 \mathrm{~cm}$ wide. The MHAQ formulation attracts mosquitoes to enter and leave the trap through a row of holes located at the top of the station. The inside of the trap has a black surface with a bottle screw adapter at the bottom. The MHAQ solution bottle can be easily screwed to the base, which is convenient when the solution bottle needs replacing. The design utilizes gravity flow to provide a continuous flow of the solution into the reservoir, with the flow ceasing once the reservoir is filled, ensuring the availability of the formulation for up to 2 months. Traps were lined with paper towels as an oviposition substrate for Aedes spp. mosquitoes, and mosquitoes that were exposed to the solution became contaminated with MHAQ when they entered the trap to oviposit on the paper towel and remained contaminated when they exited to find other containers.

\section{Evaluation of dose response to MHAQ}

Larval bioassays were performed using the standard WHO larval bioassay [28]. Eight different concentrations of MHAQ (0.02 ppm to $1.28 \mathrm{ppm}$ ) were used, resulting in a range of larval mortality from 0 to $100 \%$. A total of $100 \mathrm{Ae}$. aegypti third-instar larvae were exposed to each of the concentrations, and 50 larvae were exposed to a control containing distilled water with no insecticide. Each cup containing a specific concentration of MHAQ was made by mixing $99 \mathrm{ml}$ of distilled water and $1 \mathrm{ml}$ of insecticide according to the desired concentration. The control treatment consisted of $99 \mathrm{ml}$ of distilled water and $1 \mathrm{ml}$ acetone, and each concentration was replicated four times. Pupal mortality was recorded after an exposure of $24 \mathrm{~h}$, and the lethal concentration $\left(\mathrm{LC}_{50 / 90}\right)$ was calculated.

To obtain the emergence inhibition (EI), preliminary tests were conducted by exposing the test larvae to a wide range of concentrations. Based on these results, nine different concentrations $(0.07 \mathrm{ppb}-0.70 \mathrm{ppb})$ of MHAQ were used, yielding between 5 and $95 \%$ in the range of EI. The bioassays were performed using $20 \mathrm{Ae}$. aegypti third-instar larvae for each concentration. The larvae were placed into a $250-\mathrm{ml}$ paper cup containing $99 \mathrm{ml}$ distilled water and $1 \mathrm{ml}$ insecticide and then placed inside a mosquito cage. The control treatment contained $99 \mathrm{ml}$ distilled water and $1 \mathrm{ml}$ acetone, and five replicates were tested for each concentration. Due to the delayed action of pyriproxyfen, larval and pupal mortalities were assessed every day until all individuals had either emerged or died in the control group. Throughout the study, larvae were provided with TetraMin ${ }^{\circledR}$ fish food at $100 \mathrm{mg} /$ liter until pupae emerged [29, 30]. For each bioassay, the temperature was maintained at $26 \pm 4{ }^{\circ} \mathrm{C}$ with $60 \pm 20 \%$ RH and a 12-h light: 12 -h dark photoperiod.

\section{Transfer of MHAQ to untreated containers}

To demonstrate the transfer of MHAQ to another container, binary choice tests were performed in a small mosquito cage $(\mathrm{L}: 30 \times \mathrm{W}: 30 \times \mathrm{H}: 30 \mathrm{~cm})$ under laboratory conditions of $26 \pm 2{ }^{\circ} \mathrm{C}$ and $60 \pm 20 \% \mathrm{RH}$, based on the studies by Chism \& Apperson [24] and Sihuincha
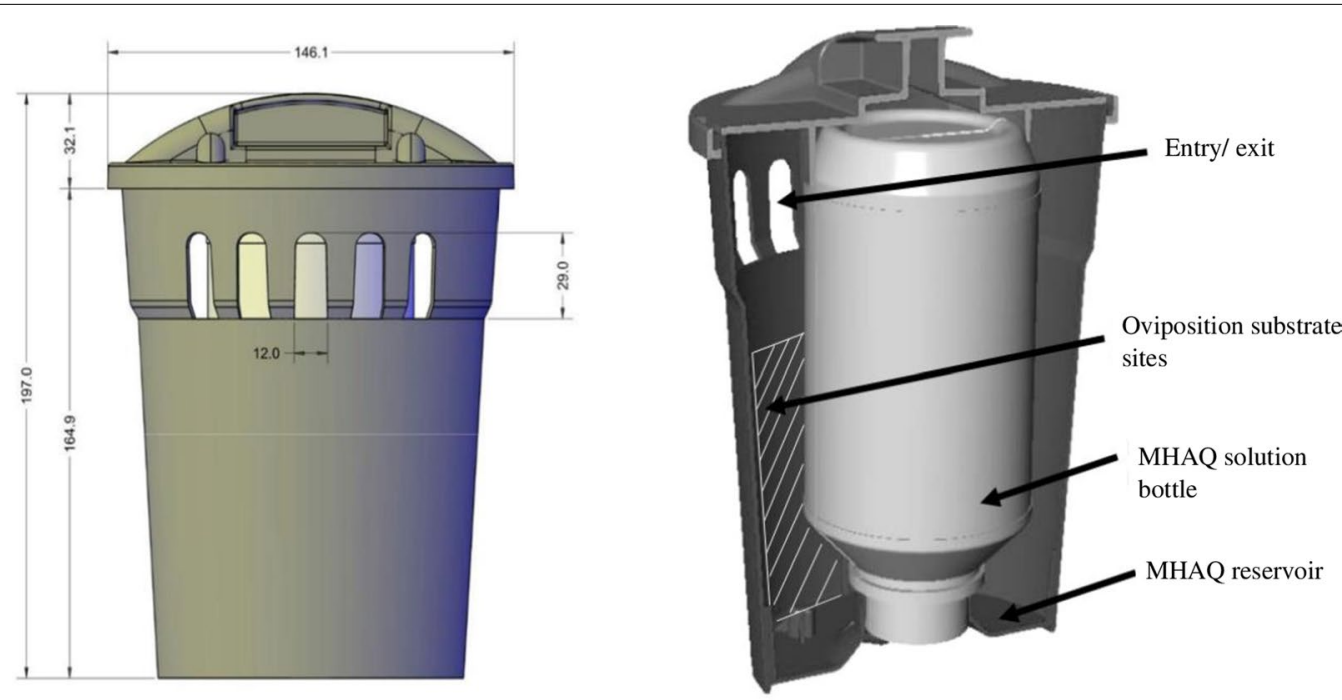

Fig. 1 Cross section and schematic image of the MHS and MHAQ solution bottle 
et al. [31]. A binary choice test [24] was performed with each cage holding a batch of gravid females (1-2 weeks old, 4 days post-blood-feeding). Two ovitraps $(250 \mathrm{ml}$ capacity, $7.2 \mathrm{~cm}$ diameter, $9 \mathrm{~cm}$ height) were placed by simple randomization in diagonal corners of each cage. The treatment cage contained two ovitraps: one with an oviposition strip treated with MHAQ and the other with an untreated filter paper in tap water only. The control cage also contained two ovitraps, both lined with untreated filter paper and filled with $100 \mathrm{ml}$ tap water. The MHAQ was prepared as an emulsifiable form to be released effectively during oviposition of the mosquito [20]. Cotton balls soaked with $10 \%$ sucrose were supplied in each cage.

Gravid female mosquitoes from the same batch were given a dual choice [24] between the particular concentration of MHAQ and tap water under the following conditions: (1) one gravid with $0.5 \mathrm{ppm},(2)$ one gravid with $10 \mathrm{ppm}$, (3) one gravid with $20 \mathrm{ppm}$, (4) one gravid with $40 \mathrm{ppm}$, (5) three gravid with $0.5 \mathrm{ppm},(6)$ three gravid with $10 \mathrm{ppm}$, (7) three gravid with $20 \mathrm{ppm},(8)$ three gravid with $40 \mathrm{ppm}$, (9) five gravid with $0.5 \mathrm{ppm}$, (10) five gravid with $10 \mathrm{ppm}$, (11) five gravid with $20 \mathrm{ppm}$, and (12) five gravid with $40 \mathrm{ppm}$ of MHAQ. To ensure that ovitrap placement did not influence oviposition choice, the ovitrap was rotated clockwise over time in each replicate of each experiment. Each treatment was replicated five times, and the complete assays were repeated three times. The mosquitoes were left to lay eggs, and all the samples and equipment were discarded after $72 \mathrm{~h}$. Twenty larvae were introduced into water samples collected from ovitraps filled with tap water (treatment cage and control cage) and monitored daily until all the larvae and pupae in the control ovitraps had either died or emerged as adults. Successful MHAQ contamination and transferability were evaluated by comparing the differences in larvae/pupal mortality and EI of each ovitrap between treatment and control experiments.

\section{Oviposition preferences of Aedes aegypti to MHAQ in competition with water}

The oviposition site selection bioassay procedures have been slightly modified based on previous reports [32, 33]. The attraction of Ae. aegypti to commercial MHAQ solutions in the presence of multiple oviposition sites was determined using a cage containing 60 females (3-5 days non-blood-fed) and 15 males (2-5 days old), and blood meal was offered after $30 \mathrm{~min}$ of combining. After 3 days of blood-feeding, 15 females were randomly transferred to a new cage containing four oviposition cups filled with a Whatman ${ }^{\circledR}$ No. 1 filter paper (Merck Millipore, USA) and $200 \mathrm{ml}$ of the following solutions: (i) MHAQ solution-MHAQ, (ii) Hay Infusion-HI, (iii) tap

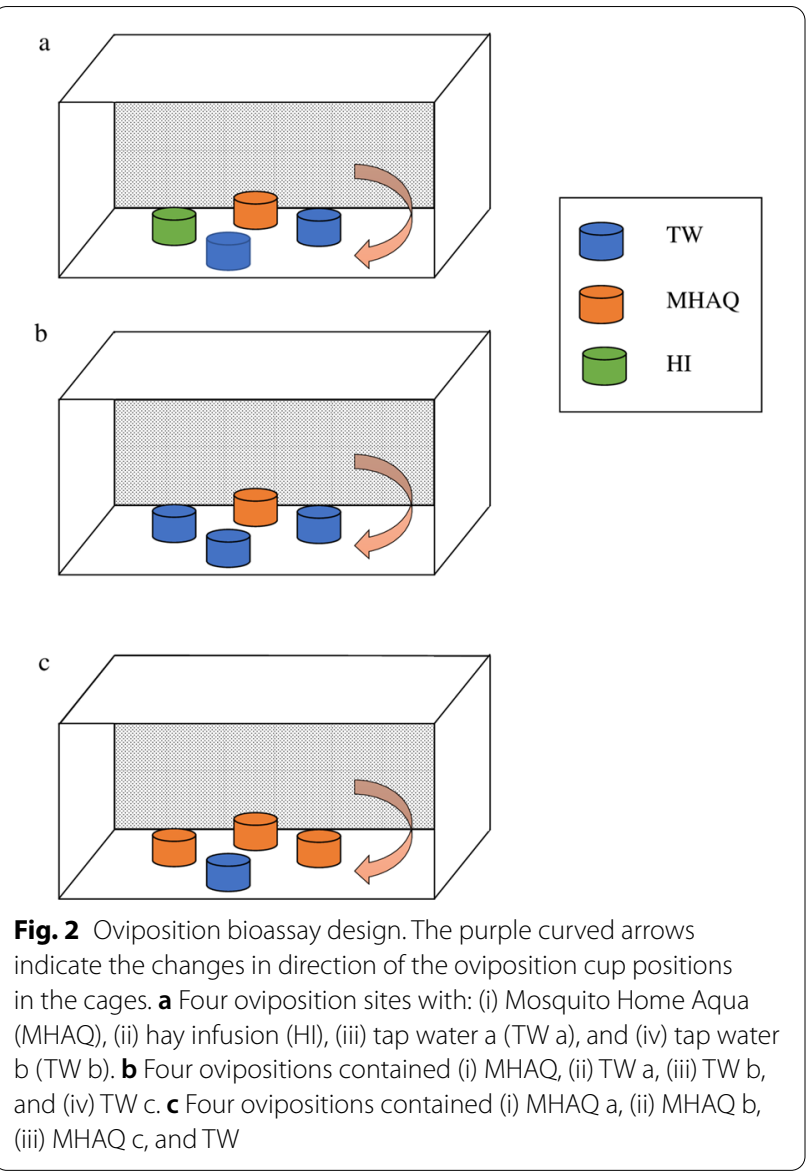

water a-TW a, and (iv) tap water $\mathrm{b}-\mathrm{TW} \mathrm{b}$, respectively (Fig. 2a).

In a second experiment, the preference of female mosquitoes to oviposit in small water sources was determined by exposing 15 females to the following solutions: (i) MHAQ, (ii) TW a, (iii) TW b, and (iv) TW c (Fig. 2b). In addition, the preference of mosquitoes to oviposit in various containers was also assessed in the third experiment using the MHAQ a, MHAQ b, MHAQ c, and TW a solutions (Fig. 2c). Every oviposition site containing MHAQ solution and tap water in each experiment was replicated four times, and the position of the cup was randomized (Fig. 2). A new batch of 15 females was used in each experimental replicate. In all three experiments, the mosquitoes were allowed to lay eggs for 3 days on the Whatman $^{\circledR}$ No. 1 filter paper, and their egg deposition was assessed through examination of the filter paper.

\section{Residual larvicide activity of MHAQ}

To assess the residual larvicidal activity of MHAQ, four different concentrations $(0.5 \mathrm{ppm}, 1.0 \mathrm{ppm}, 20 \mathrm{ppm}$, and $40 \mathrm{ppm}$ ) were evaluated in laboratory settings and covered with a net to prevent ovipositing of any mosquitoes. 
Five beakers (15 cm diameter $\times 18 \mathrm{~cm}$ height) were placed approximately $30 \mathrm{~cm}$ from each other, with four beakers filled with 2.01 of different MHAQ solution concentrations and the remaining beaker with tap water as a control. These bioassays were performed in replicates of three for every concentration and control. Batches of 20 larvae were released on day 0 , with the replacement of larvae carried out every 10 days via the introduction of new larvae batches, and observation was conducted for 90 days. Every time larvae were replaced, all the larvae and pupae were counted and removed and the surviving larvae transferred into paper cups for further observations. Larvae were supplied with TetraMin ${ }^{\circledR}$ fish food, and experiments were carried out at $26 \pm 4{ }^{\circ} \mathrm{C}$ and $60 \pm 20 \%$ RH with a 12:12 day:night photoperiod.

\section{Effect of MHAQ on fecundity and fertility}

Colonies of Ae. aegypti were subjected to a sublethal dose $\mathrm{LC}_{50}$ [34] (where $50 \%$ of the mosquitoes could still be alive and capable of producing first-generation progeny) of MHAQ following the WHO larval bioassay method. After 24-h exposure, the surviving larvae were transferred and allowed to emerge in emergence cages. The larvae were fed TetraMin ${ }^{\circledR}$ fish food, while the adult mosquitoes were fed $10 \%$ sucrose solution. After 3 to 5 days, 30 male and female mosquitoes were transferred into oviposition cages for cohabitation, and $30 \mathrm{~min}$ after combining, the mosquitoes were provided with guinea pig blood for $2 \mathrm{~h}$. Fully engorged mosquitoes were then transferred to a new cage and supplied with a $10 \%$ sucrose solution. Three days of blood meal was provided; 15 females were transferred to individual plastic cups that were covered with a net and lined internally with a Whatman ${ }^{\circledR}$ No. 1 filter paper as an oviposition substrate. The females were allowed to oviposit their eggs for 5 days, and the number of eggs was counted daily [18]. Eggs collected during the fecundity test were used in the fertility test by immersing the filter paper with the eggs into the tap water in the culture trays. The number of larvae that hatched was monitored and recorded, and the experiments were carried out at $26 \pm 4{ }^{\circ} \mathrm{C}$ and $60 \pm 20 \% \mathrm{RH}$ with a $12: 12$ day:night photoperiod.

\section{Adult wing length}

It is known that the adult wing length correlates with the fecundity and body size of mosquitoes. After the adults emerged from the fertility studies, a total of 30 Ae. aegypti mosquitoes (males and females) were anesthetized and killed. All the right wings were removed, and the length of the wings was measured from the axial vein to the radius 1 (R1) vein using a stereomicroscope $(100 \times)$.

\section{Small-scale field trials}

According to WHO guidelines, new products that have shown promising results in laboratory studies (Phase I) should be evaluated under Phase II. At this point, a proof of concept was required, i.e. the MHAQ could be transferred to other containers by wild mosquitoes and subsequently the larvae could be killed. The study sites were located in the Petaling District, Shah Alam, Selangor, and two similarly isolated areas were selected: Dataran Automobil as the treatment area $\left(19^{\circ} 57^{\prime} 05^{\prime \prime} \mathrm{S}, 43^{\circ} 76^{\prime} 88^{\prime \prime}\right)$ and Seksyen 16 as the control area $\left(19^{\circ} 57^{\prime} 05^{\prime \prime} \mathrm{S}, 43^{\circ} 76^{\prime} 88^{\prime \prime}\right)$. The distance between the treatment and the control site was approximately $1.8 \mathrm{~km}$, and both areas have been declared dengue 'hotspots', with continuous dengue cases being reported, and shared a similar housing structure with good access to sanitation. Dataran Automobil was selected as a treatment area because it is more vulnerable than Seksyen 16 and is closer to our workstation in Shah Alam.

The trial consisted of a 2-month pre-treatment period (November-December 2017), 6 months of treatment, and 1 month of post-treatment (January 2018-July 2018). In the treatment and control areas, 48 ovitraps were placed in each area, with a total of 96 ovitraps [20,32]. All the ovitraps were randomly positioned in the potential container, such as under roofs, near vegetation sheds, water supplies, and near human activities areas. Each ovitrap cup was individually coded with labels to ensure it was placed at the same location in each sampling round and any missing ovitrap or paddle was replaced with a new one.

During the treatment phase, from the third month onwards, a total of $48 \mathrm{MHS}$ stations were deployed at a distance of 1 to $10 \mathrm{~m}$ from the nearest ovitrap across the treatment site from January 2018 to June 2018. The stations were only deployed at the treatment site and serviced on a fortnightly basis to ensure that they were completely operational, that there was sufficient volume of the solution, and that any clogged devices were removed. The stations were then examined and the remaining solutions and paper substrates were collected and brought back to the laboratory for larval bioassay assessment.

The ovitraps and MHS were taken to the laboratory separately, and the contents of each MHS and ovitrap, such as water, paddles, and paper substrates, were transferred to an enamel pan to facilitate the observation of mosquito juveniles and attached eggs. All larvae were identified [35], and total intact eggs (hatched or unhatched) and live larvae were counted and recorded.

The impact of treatment using the MHS to deliver MHAQ to other ovitraps was determined using larval bioassays as defined in the WHO guidelines. In the case 
of ovitrap containers, water samples from treatment and control areas were tested at three different time points: pre-intervention, intervention, and post-intervention. In addition, although water samples from the MHS were available only during the treatment period, these samples were also tested. Larval bioassays were performed using late third-instar larvae of the Ae. aegypti. Control treatments were treated with $199 \mathrm{ml}$ tap water and $1 \mathrm{ml}$ of acetone while three cups were set up using tap water and 20 larvae per bioassay as negative controls. Mortality was recorded every $24 \mathrm{~h}$ until adult emergence, and larvae were also provided with food daily. In certain samples, pyriproxyfen contamination increased the larval development time from a typical 8 to 9 days up to 14 days, resulting in pupae death. The experiments were conducted at $26 \pm 2{ }^{\circ} \mathrm{C}, 60 \pm 20 \% \mathrm{RH}$, and preferably a photoperiod of $12 \mathrm{~h}$ light followed by $12 \mathrm{~h}$ dark.

\section{Statistical analysis}

All statistical analyses were conducted using the Statistical Package for the Social Science (SPSS) version 23. In each assay, the data sets were tested for normality distribution using the Shapiro-Wilk test. Prior to analysis, the $\log _{10}$ values of the data were obtained. If the data were normally distributed, a parametric test was performed, followed by a Tukey post hoc test. However, if the data were not normally distributed, a non-parametric test was applied [36].

All data for each treatment bioassays were presented as a mean \pm SE unless specified otherwise. For the larvae bioassay test, data were analyzed using the probit analysis. The EI was calculated using the following formula [37]:

Percentage of inhibition of emergence $=100-100(T / C)$

where $T$ is the number of emergence in treated containers, and $C$ is the number of emergence in control containers. Control mortality > 5\% was corrected using Abbott's formula [38].

Mortality data for the larval bioassay were recorded and presented as a percentage, with all data calculated using the log-probit analysis. Results were presented as $\mathrm{LC}_{50}$ (lethal concentration in $\mathrm{ppm}$ for $50 \%$ death) and $\mathrm{LC}_{90}$ (lethal concentration in ppm which caused $90 \%$ mortality).

The effective reduction (ER) percentage was calculated as:

$$
\mathrm{ER} \%=[\mathrm{NC}-\mathrm{NT} / \mathrm{NC}] \times 100
$$

where $\mathrm{NC}$ is the number of eggs in the control group and NT is the number of eggs in the treatment group. Student's t-test was used to compare fertility, fecundity, and wing length of Ae. aegypti between the control and treated groups. A Mann-Whitney test was performed when normality was not met.

The comparison of oviposition attractants was performed using a one-way ANOVA test followed by a Tukey post hoc test. The impact of the oviposition site with MHAQ, HI, and TW was assessed with a one-way ANOVA test, followed by a Tukey post hoc test where necessary. All the results of the analysis with $p<0.05$ were considered statistically significant. For the residual activity trials, analysis of the concentration effects, pupal mortality, and their interactions was performed using two-way repeated measures ANOVA and the Greenhouse-Geisser correction. The transfer activities of MHAQ in the laboratory and field trials were analyzed for each concentration for successful adult emergence using a one-way ANOVA with a Tukey post hoc test between the means $(p<0.05)$.

\section{Results}

Susceptibility of Ae. aegypti to MHAQ

The response dose range was established based on the third-instar Ae. aegypti larvae. Mortality of the Ae. aegypti was recorded approximately $24 \mathrm{~h}$ after exposure in the laboratory bioassay, and it was observed that MHAQ effectively killed the Ae. aegypti larvae at $24 \mathrm{~h}$ exposure with a $\mathrm{LC}_{50}$ of $0.0903 \mathrm{ppm}(95 \% \mathrm{CL}=0.0827-$ $0.0986)$ and $\mathrm{LC}_{90}$ of $0.237 \mathrm{ppm}(95 \% \mathrm{CL}=0.237-0.286$ ). Meanwhile, the $\mathrm{EI}_{50}$ and $\mathrm{EI}_{90}$ of Ae. aegypti exposed with MHAQ were $0.323 \mathrm{ppb}(95 \% \mathrm{CL}=0.065-0.89)$ and $0.102 \mathrm{ppb}(95 \% \mathrm{CL}=0.059-0.141)$, respectively.

\section{Transfer of MHAQ from treated to untreated ovitraps}

The ability of one, three, and five mosquitoes to transfer MHAQ to the untreated containers was determined, and larvae were significantly prevented from developing into adults compared to the control groups (ANOVA, $F_{(6}$,

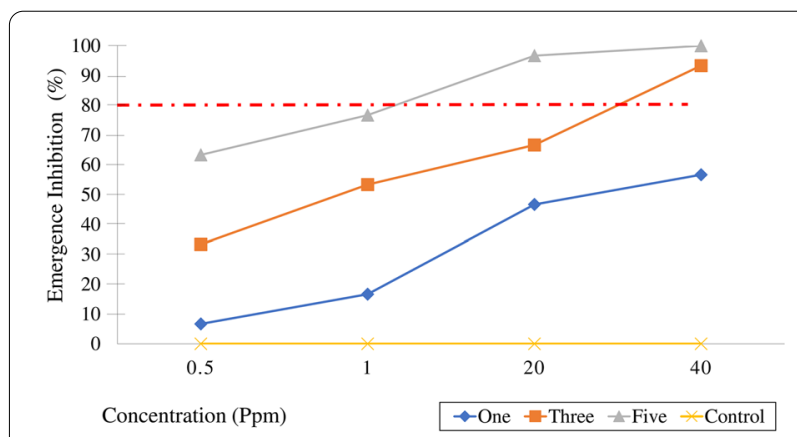

Fig. 3 Aedes aegypti as transportation for MHAQ transfer: Emergence inhibition over the MHAQ different concentrations for Ae. aegypti in untreated water. The red dashed line shows the threshold value of $80 \%$ above which the insecticide is considered effective 
Table. 1 Mean number ( $\pm S E$ ) of eggs laid in treated and untreated ovitraps with different ranges of MHAQ concentration and number of mosquitoes

\begin{tabular}{|c|c|c|c|c|}
\hline \multirow{2}{*}{$\begin{array}{l}\text { No. of } \\
\text { mosquitoes }\end{array}$} & \multirow{2}{*}{$\begin{array}{l}\text { Concentration } \\
\text { (ppm) }\end{array}$} & \multicolumn{2}{|c|}{ Mean no. of eggs laid } & \multirow[t]{2}{*}{$P$-value } \\
\hline & & Treated & Untreated & \\
\hline \multirow[t]{4}{*}{ One } & 0.5 & $16.00 \pm 2.31^{\mathrm{a}}$ & $9.00 \pm 2.00^{\mathrm{a}}$ & 1.00 \\
\hline & 1.0 & $6.33 \pm 2.19^{a}$ & $5.51 \pm 3.18^{\mathrm{a}}$ & 0.38 \\
\hline & 20 & $8.67 \pm 2.03^{a}$ & $9.00 \pm 2.65^{a}$ & 0.61 \\
\hline & 40 & $12.67 \pm 2.85^{\mathrm{a}}$ & $7.00 \pm 3.61^{\mathrm{a}}$ & 0.64 \\
\hline \multirow[t]{4}{*}{ Three } & 0.5 & $57.00 \pm 11.14^{\mathrm{a}}$ & $47.00 \pm 10.44^{\mathrm{a}}$ & 0.78 \\
\hline & 1.0 & $42.67 \pm 10.33^{\mathrm{a}}$ & $16.67 \pm 5.24^{\mathrm{a}}$ & 0.28 \\
\hline & 20 & $31.33 \pm 7.75^{\mathrm{a}}$ & $23.00 \pm 4.16^{\mathrm{a}}$ & 0.21 \\
\hline & 40 & $48.00 \pm 11.72^{\mathrm{a}}$ & $18.33 \pm 6.69^{a}$ & 0.38 \\
\hline \multirow[t]{4}{*}{ Five } & 0.5 & $67.67 \pm 32.35^{\mathrm{a}}$ & $40.33 \pm 7.13^{\mathrm{a}}$ & 0.12 \\
\hline & 1.0 & $114.33 \pm 32.85^{a}$ & $62.67 \pm 24.91^{a}$ & 0.04 \\
\hline & 20 & $66.67 \pm 16.83^{a}$ & $47.67 \pm 19.92^{a}$ & 0.93 \\
\hline & 40 & $78.00 \pm 21.20^{\mathrm{a}}$ & $51.33 \pm 8.65^{\mathrm{a}}$ & 0.11 \\
\hline
\end{tabular}

Groups in the same row that shows a different letter are significantly different $(p<0.05)$

$\left.{ }_{24)}=3.97, p<0.007\right)$. For treatment groups, the five-mosquito group transferred the most MHAQ and had the highest EI compared to the other groups. However, there was no significant difference in the groups of three and five females at $40 \mathrm{ppm}$ of MHAQ with an EI\% between 93.3 and $100 \%$ (Fig. 3). Table 1 shows the exposure of different numbers of mosquitoes at oviposition sites treated with different concentrations of pyriproxyfen. The results revealed that there was no significant difference between the number of eggs laid in the treated and untreated water by a different number of mosquitoes. It was evident that even at high concentrations, MHAQ did not affect the number of eggs that had been laid.

\section{Aedes aegypti oviposition activities to MHAQ in competition with water}

Three different types of bioassays were used to observe the oviposition preference of Ae. aegypti between MHAQ. For the first bioassay, oviposition sites were divided into either MHAQ, HI, TW a, or TW b. Gravid Ae. aegypti females laid their eggs in all the cups, and a total of 2107 eggs were recorded. The maximum mean number of eggs laid was in the HI $(365.00 \pm 57.14)$, followed by TW b $(191.75 \pm 60.72)$, TW a $(183.50 \pm 44.58)$ and MHAQ (16.75 \pm 6.93$)$. There was a significant difference between the mean number of eggs in the MHAQ with HI and TW (ANOVA, $F_{(3,12)}=13.003, p=0.0004$ ). However, no significant difference was observed between TW a and TW $b$ in this assay ( $p>0.05)$ (Fig. $4 a)$.

For the second bioassay, a comparison among four cups (three TW and one MHAQ) was conducted to evaluate

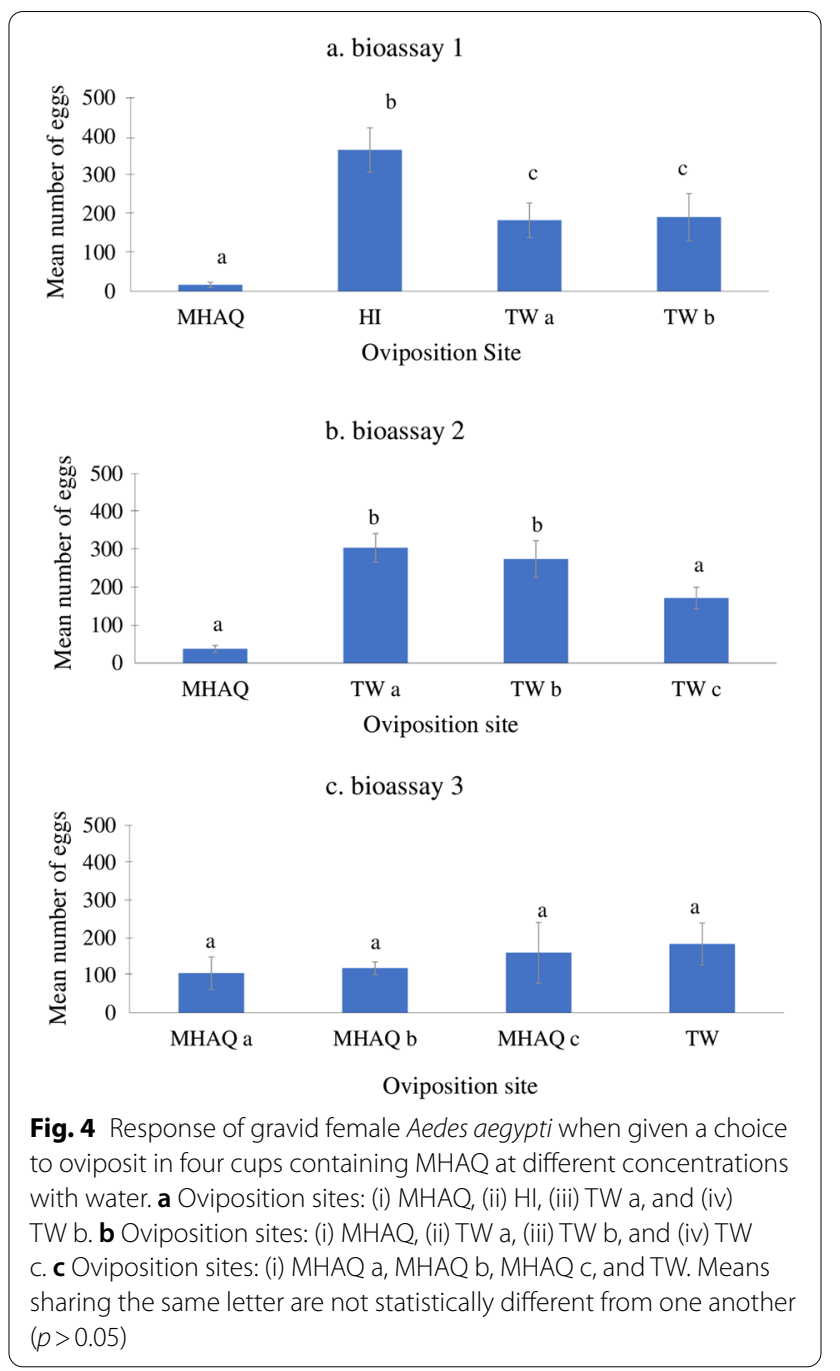

the oviposition site preference of gravid Ae. aegypti, with eggs also laid in all four cups. However, only $4.2 \%$ of eggs were deposited in a cup containing MHAQ $(\mathrm{MA}=37.5 \pm 8.93)$ while $95.8 \%$ were deposited in the cups filled with tap water (TW a: $304.25 \pm 37.82$; TW b: $274.5 \pm 48.56$; TW c: $172.25 \pm 28.83$ ) (Fig. $4 b)$. There was a significant difference between the two types (MHAQ and TW) of attractants used for oviposition (ANOVA, $\left.F_{(3,12)}=12.359, p=0.001\right)$. However, there was no significant difference in the mean number of eggs collected in the TW a and TW $c(p>0.05)$.

In the third bioassay, three cups were filled with MHAQ a, MHAQ b, and MHAQ $\mathrm{c}$ and one with TW, with eggs oviposited in all the cups. A total of 2269 eggs were laid in all the cups, with $68 \%$ of the eggs in the cups baited with MHAQ solutions and $32 \%$ of the eggs in the cups baited with TW, resulting in the highest number of eggs laid in the TW cups. Moreover, there was no significant difference between the mean number of eggs 


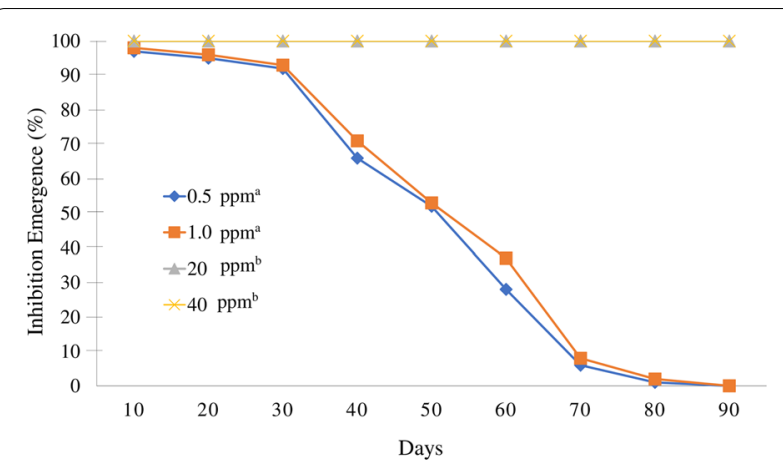

Fig. 5 Residual effects of MHAQ at different concentrations on Ae. aegypti larvae. The values at each point (every 10 days) represent the mean pupal mortality \pm SE (\%). The MHAQ concentrations with significant differences are represented by different superscript letters (repeated measures ANOVA; $p<0.001$ by Tukey post hoc test)

collected across the treatments (ANOVA, $F_{(3,12)}=0.442$, $p=0.727$ ) (Fig. 4c).

\section{Residual larvicide activity of MHAQ}

From day 10 to day 90, there was greater efficacy of the MHAQ at the higher concentrations of $40 \mathrm{ppm}$ and $20 \mathrm{ppm}$. At the lower concentrations $(0.5 \mathrm{ppm}$ and $1.0 \mathrm{ppm}$ ), there was $>90 \%$ mortality until day 30 until a $<80 \%$ decrease in pupal mortalities on day 40 . There was no pupal mortality on day 90 . Based on laboratory trials, the residual activity of the MHAQ achieved $>80 \%$ mortality for 30 days and continued for 90 days (Fig. 5). The interaction between the MHAQ concentration and time was statistically significant based on a repeated measure ANOVA and the Greenhouse-Geisser correction on the number of pupal mortalities (time, $F_{(3.77,94.21)}=547.21$, $p<0.001$; treatment, $F_{(4,25)}=7020.44, p<0.001$, treatment $\times$ time, $\left.F_{(15.07,94.21)}=205.71, p<0.001\right)$.

\section{The effect of MHAQ on fecundity, fertility, and wing length}

It was found that the $\mathrm{LC}_{50}=0.0903 \mathrm{ppm}$ significantly reduced the number of eggs laid in the treatment group compared to the control group (Student's $t$-test: $t=7.509$; $\mathrm{df}=18 ; p<0.05)$. The mean number of eggs laid by $A e$. aegypti was $53.70 \pm 13.64$, compared to $112.80 \pm 20.82$ in the control group $(p<0.05)$ (Student's $t$-test for a single sample: $t=8.355 ; \mathrm{df}=10 ; P<0.001)$, indicating a $50 \%$ reduction in the mean number of eggs laid in the treatment group compared to the control group.

There was also a significant difference (Student's $t$-test: $t=-5.489 ; \mathrm{df}=18 ; p<0.05)$ in the percentage of eggs hatching in the control group $(92.80 \%)$ and the treatment group that was exposed to a sublethal dose of MHAQ $(70.67 \%)$. The $\mathrm{ER} \%$ was $\approx 23.46$, which was significantly different from zero (Student's t-test for a single sample: $t=5.023 ; \mathrm{df}=10 ; p<0.001)$, suggesting a decrease in the rate (percent) of hatching in the treatment group by $20 \%$ compared to the control group. On the other hand, the wing lengths of male mosquitoes that had the sublethal treatment were significantly different from the wing lengths of male mosquitoes in the control group (MannWhitney U-test: $U=2.5, \quad Z=-6.6635, \quad p<0.0001)$. The effects were similar for female mosquitoes, where the wing lengths of those that had the sublethal treatment were significantly different from those in the control group (Mann-Whitney U-test: $U=0, Z=-6.662$, $p<0.0001$ ) (Table 2).

\section{Efficacy of small-scale field trials}

Egg collections were carried out from both ovitrap and MHS to determine the preference of the mosquitoes between TW and MHAQ. During the intervention period, MHS with MHAQ formulations were most effective in attracting Aedes compared to ovitrap, with a significantly greater collection in MHS (1176.15 \pm 57.84$)$ than in ovitrap (858.82 \pm 59.87$)$ (ANOVA: $F_{(1,94)}=14.57$, $p<0.001)$. After 4 weeks of MHS implementation, an increased number of eggs collected was observed in week 12 , and this was consistently observed until the end of week 30. Based on a repeated measure ANOVA and the Greenhouse-Geisser correction, there was a significant difference in the average eggs that were collected between multiple time points $\left(F_{(7.88,740.75)}=15.24, p<0.001\right.$; treatment $\times$ time, $\left.F_{(7.88,740.75)}=3.67, p<0.001\right)$. In addition, the number of eggs collected fluctuated with some variation due to other environmental factors (Fig. 6).

In the small-field trials, autodissemination of MHAQ was detected in the ovitraps. In the ovitrap and MHS, the mortalities of pupas exposed to the water sample during the intervention periods were significantly higher than in

Table. 2 Effects of MHAQ on fecundity, fertility, and wing length on Aedes aegypti mosquitoes

\begin{tabular}{lll}
\hline Parameter & Treated & Control \\
\hline Fecundity & & \\
No. of eggs laid & $53.70 \pm 13.64^{\mathrm{a}}$ & $112.80 \pm 20.82^{\mathrm{b}}$ \\
ER (\%) & 52.40 & \\
Fertility & & \\
No. of hatching eggs & $70.67 \pm 3.64^{\mathrm{a}}$ & $92.80 \pm 1.72^{\mathrm{b}}$ \\
ER (\%) & 23.46 & \\
Wing length (mm) & & \\
Female & $2.23 \pm 0.06^{\mathrm{a}}$ & $2.63 \pm 0.05^{\mathrm{b}}$ \\
Male & $2.09 \pm 0.03^{\mathrm{a}}$ & $2.19 \pm 0.04^{\mathrm{b}}$ \\
\hline
\end{tabular}

Groups in the same row that shows a different letter are significantly different $(p<0.05)$ 


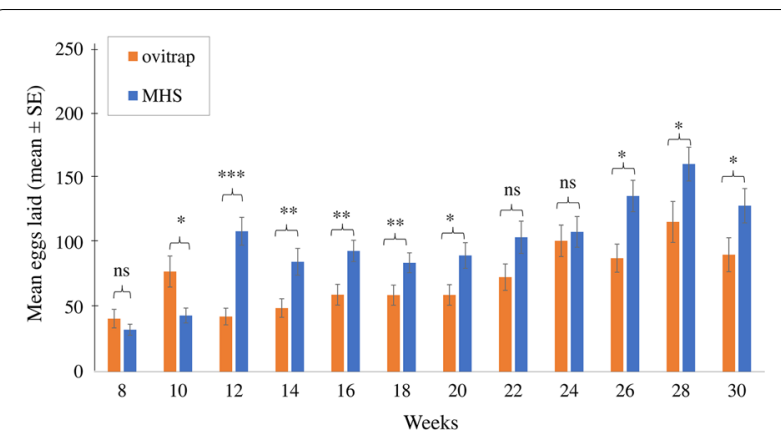

Fig. 6 The mean number of eggs ( \pm SE) collected in the ovitraps and MHSs during intervention period at small-scale field trials $(n=48)$. Significant differences are indicated by asterisks (repeated measureANOVA, ${ }^{*} p<0.05,{ }^{* *} p<0.01,{ }^{* * *} p<0.001$, ns $=$ not significant)



the control samples, where pupal mortality in the ovitrap was $28.07 \pm 4.42 \%$ at week 10 , which was consistent during the trials and peaked at $42.63 \pm 11.46 \%$ at week 26. There was a small decrease in mortality at week 14 $(14.61 \pm 2.03)$. After 12 weeks of intervention, the overall mortality in the trials was $27.01 \pm 1.8 \%$, and $100 \%$ pupal mortality was observed in both the ovitraps and the MHS (Fig. 7).

\section{Discussion}

Dengue fever is a disease caused by mosquitoes that significantly impacts human health. However, existing vector management methods have failed to reduce dengue infections, indicating that these methods may not be sufficient and require improvements. Pyriproxyfen autodissemination is a novel strategy for dispersing pyriproxyfen into oviposition containers through the manipulation of the 'skip oviposition' behavior of mosquitoes. The study aimed to determine the effectiveness of MHS using autodissemination strategies based on laboratory and small-scale field studies.

Multiple choice of egg-laying site tests and larval bioassays revealed that Ae. aegypti was highly susceptible to low concentrations of MHAQ, which affected the fecundity, fertility, and wing size of the mosquitoes. In this study, MHAQ was more effective in killing Ae. aegypti larvae after a 24-h exposure, with the $\mathrm{LC}_{90}=0.237 \mathrm{ppm}$, which was lower compared to a previous study $\left(\mathrm{LC}_{90}=10 \mathrm{ppm}\right)$ [39]. The $\mathrm{EI}_{50}$ rate obtained was $0.323 \mathrm{ppb}$, which was consistent with other studies that reported low $\mathrm{EI}_{50}=0.56 \mathrm{ppb}$ [23], $0.353 \mathrm{ppb}, 0.219 \mathrm{ppb}$ [40], and $0.008 \mathrm{ppb}$ [41]. Furthermore, Paul et al. [42] showed that pyriproxyfen effects were more toxic against Ae. aegypti than other insecticides (methoprene, diafenthiuron, and tebufenozide). The dose-response test result obtained in this study differed from others, which could be due to the mosquito strain selections used in the experiments [43], different pyriproxyfen formulations [44], the material of the test containers [45], and experimental conditions. It was reported by Suman et al. [45] that the efficacy of pyriproxyfen was positively associated with the type of substrate used during the study. The $\mathrm{LC}_{50}$ value in tires was found to be 50 -fold higher compared to glass containers, and it has been suggested that the pyriproxyfen was adsorbed by the substrate used [45]. There have so far been no reports of Aedes spp. resistance to pyriproxyfen in Malaysia; thus, it can be used as an alternative insecticide in dengue control programs [46].

In the present study, MHAQ exposure at the selected dose significantly reduced the fecundity, fertility, and wing length of the Ae. aegypti mosquitoes. The size of female mosquitoes is important as larger females produce more eggs and contribute more to the mosquito populations. Exposure to pyriproxyfen has been demonstrated to affect the reproductive capacity of Aedes spp. through inhibition of vitellogenesis during egg formation [47], which is desirable since the production of a high number of eggs and optimal fertility are two key factors that influence the survival of mosquitoes [48]. Moreover, Suttana et al. [49] found a reduction in fertility and fecundity after only $5 \mathrm{~min}$ of exposure to pyriproxyfen. On the other hand, although there was no significant difference recorded in the number of eggs laid, Rhyne et al. [50] reported a lower hatching rate in treated containers compared to the controls. However, the effects of pyriproxyfen may vary among mosquitoes depending on exposure time, the concentration used, mode of delivery, and other factors [51]. Pyriproxyfen also affects the fertility and fecundity rates of the mosquitoes; however, the mechanism of action remains uncertain and requires further investigation [52-54]. 
The study conducted on horizontal transfer of MHAQ was crucial as it demonstrated successful autodissemination by the adult Ae. aegypti from treated to untreated sites. It would also be useful to target the gravid female mosquitoes at their resting sites as this may increase the amount of insecticide that can be transferred to other oviposition sites. In addition, Chism et al. [24] found that the larval mortality in an untreated site could be associated with the number of eggs laid and the residence time in the containers. The longer the time it takes for mosquitoes to lay eggs, the greater their chances of depositing more MHAQ at the untreated sites. The findings of this study provided evidence, in principle, that the MHAQ solution can be significantly transferred from contaminated containers to gravid females, who then transfer it to other oviposition sites. It was found that autodissemination activity increased with the number of female mosquitoes, and the highest EI was observed when five Ae. aegypti were introduced to 20 and $40 \mathrm{ppm}$ of MHAQ during the assays. To provide optimal control, the MHAQ needs to be disseminated by a large number of mosquitoes in particular sites, with higher numbers of mosquitoes thought to be able to transfer more chemicals compared to smaller numbers. During these trials, it was presumed that the gravid females would be more contaminated with higher MHAQ concentrations over time during oviposition.

Autodissemination using a powdered formulation of pyriproxyfen is impractical, as its application causes the accumulation of granules at the bottom of the container over some time [55]. Because of this, the MHAQ solution was evaluated concerning its capability in transferring different concentrations of pyriproxyfen to other containers under laboratory conditions. In addition, this was also the first report suggesting the autodissemination approach using commercial MHAQ-treated water to control Ae. aegypti populations.

Compared to tap water and MHAQ, more gravid females laid their eggs in hay infusion. MHAQ has an attractant effect, similar to hay infusion, and has been considered the "gold standard" for collecting and attracting mosquitoes [56]. Despite the preference for hay infusion, it was observed that Ae. aegypti oviposited eggs in all the treated and untreated ovitraps. Although MHAQ does not have a strong repellent effect, the females would still have an equal preference to lay their eggs in MHAQ and water under natural conditions. In addition, the laboratory test containers were chemically treated, which could be a reason why mosquitoes avoided laying their eggs in the containers and did not spend enough time in the cups. Other studies found that microbial activities in each oviposition bioassay influenced mosquito oviposition preference $[57,58]$. Thus, it remained unclear which of the numerous unknown degradants, mechanisms, and sources of the substances reduced the attraction of Ae. aegypti to MHAQ with respect to tap water in our study. Physicochemical aspects of the aquatic medium, visual cues, and the likelihood or possibility of adverse effects on larval development have been reported to be major factors affecting egg deposition decisions of female mosquitoes [59]. This study is the first report of MHAQ's effect on the ovipositional activity of mosquitoes, and it is essential to determine which of the chemical structures and compounds in the products affect the oviposition preference.

These findings also revealed the existence of the previously reported "skip oviposition" behavior. Furthermore, the effectiveness of the autodissemination technique highly depends on the Aedes mosquitoes acting as a mode of transportation to disseminate insecticide to the other containers [60]. The females distributed their eggs in multiple containers to avoid overcrowding in the same container as well as reduce the possibilities of losing all offspring due to site elimination to ensure the survival of their progeny. This finding was similar to the study conducted by Wong et al. [61] in Iquitos, where female mosquitoes laid eggs in all containers, but other parameters (food resources, size, temperature) were strictly assessed. Although gravid female Ae. aegypti and Ae. albopictus distribute their eggs at many sites, this behavior was not mutually exclusive as it may differ over time depending on the available suitable containers [62].

This study also discovered that MHAQ formulations have repellent properties against Ae. aegypti in laboratory settings, leading to a reduction in MHAQ efficacy. These are the first reported trials that assessed the efficacies of the MHS and MHAQ as new products. According to Vontas et al. [44], evaluation of all new vector control tools in testing pathway phases must be performed to ensure that one or two primary effects are obtained as a result of laboratory testing. However, there are a few criteria that need to be considered if the new product is to be tested in field trials. One of the criteria was to employ the 'stop and go' principle, which states that if a new product assay is not optimum yet but has passed the minimum efficacy threshold in the laboratory, there is merit to proceeding to the next level of testing, i.e. small-scale field evaluation. Furthermore, if the product has multiple properties (e.g. reduce fertility or repellence) and only displayed one action with an acceptable passing "indicative criterion," it is likely that extra combined effects can be measured at a later phase.

Nevertheless, results obtained from the laboratory assessment must be interpreted with caution as the tests were conducted in a well-controlled environment when making operational field decisions. A variety of biological 
parameters including type of strain and preference of egg-laying oviposition, as well as environmental parameters such as temperature, humidity, rainfall, and sunlight conditions, can all affect the efficacy of the product [63-65]. Despite laboratory tests revealing the minor repellent impact of MHAQ against mosquitoes, the number of eggs obtained in small-scale field trials was higher than the gold standard (ovitrap). Other parameters such as the chemical transference by mosquitoes and the effect on biological parameters of mosquitoes also indicate a promising outcome. The MHS could potentially be used as an autodissemination station in future control efforts. Moreover, this is the first report of the effect of MHAQ on the ovipositional activity of mosquitoes. It is essential to determine the chemical structures and compounds in the products that affect the oviposition preference.

The beneficial residual impact of MHAQ on Ae. aegypti is encouraging and has presented a prolonged action of 22 weeks by killing $100 \%$ of the larvae. With respect to the residual larvicidal activity of the commercial MHAQ solutions, concentrations of 20 and $40 \mathrm{ppm}$ were sufficient to produce $100 \%$ mortality up to 90 days. Since the MHAQ formulation can be kept inside the MHS for up to 2 months before completely evaporating, MHAQ needed to remain active for at least the 2-month period of the treatments. This slow-release formulation should be able to exhibit residual larvicidal activity to prevent the emergence of mosquitoes and, subsequently, reduce labor costs and spraying activities. Furthermore, WHO considers $\geq 80 \%$ mosquito mortality to be an effective insecticide. However, it was noted that the exposure of treated containers under laboratory settings may not reflect actual field conditions as environmental factors such as direct rainfall, organic matter, exposure to sunlight, and water exchange may reduce the efficacy of MHAQ. Therefore, further studies on MHAQ residual activity should be conducted under a wider range of settings.

The findings in the small-scale field trials were consistent with previous studies that demonstrated that MHS was an efficient tool to monitor and trap Aedes spp. mosquitoes $[66,67]$. The small-scale field trials showed that MHS consuming commercial MHAQ was highly attractive compared to conventional ovitraps among local Aedes mosquitoes. Our trials were located in the middle of the city with a high range of mosquito population, with no walls or barriers in place to prevent mosquitoes from migrating into the study area from nearby. These mosquitoes may potentially replace the local mosquito population [68], thus laying their eggs inside the MHSs, ovitrap, or both as their first choice before they reach other container habitats. It is important to address this significant factor, especially in the open field trials [69]. Apart from varying moisture levels, visual and heat cues may also affect mosquito recognition of hosts, in particular environments that produce different results. Thus, further studies are still required on whether the MHAQ is consistently more effective in different settings.

In a field setting, the efficiency of MHAQ dissemination from MHS to ovitrap was demonstrated. The occurrence of MHAQ in the ovitrap was determined, with pupal mortality ranging from $14.6 \%$ to $42.6 \%$. It was discovered that no larvae of Aedes spp. were present in the MHS stations treated with MHAQ during the MHS implementation period, leading to the hypothesis that the MHAQ formulation killed all of the hatched larvae and demonstrated the effectiveness against Ae. aegypti first-instar larvae. Our previous study using residual activity trials found that MHAQ (20 and $40 \mathrm{ppm}$ ) had 100\% mortality against Aedes mosquitoes for up to 3 months, which implied that the $100 \%$ mortality observed in the water sample collected from MHS (treatment) in the small-scale field trials was also influenced by the residual effect. Aside from that, the initial concentration of MHAQ was maintained by the replenishment of the formulation every 2 weeks. Semi-field and field trials have demonstrated that Aedes spp. can transfer pyriproxyfen from the treated containers to other larval oviposition sites, which have caused a high range of EI rates on the mosquitoes. Suman et al. [70] obtained 50.4\% pupal mortality against Ae. albopictus with a dissemination range of up to $200 \mathrm{~m}$ in residential areas while Lloyd and colleagues also reported autodissemination activities within a range of up to $200 \mathrm{~m}$ from the autodissemination vases that can be effectively used for 5 weeks against Ae. albopictus larvae [71]. Thus, it is likely that most studies used a large amount of pyriproxyfen to increase the impact of autodissemination under semi-field and field conditions [72].

The occurrence of various factors has limited the capability to investigate a broader aspect against the local mosquito population. In addition, incoming mosquitoes may also play an important role in increasing the coverage of pyriproxyfen dissemination, which, unfortunately, may lead to the failure of specific experiments [73]. The oviposition preference of mosquitoes has a complex effect on understanding local populations following the use of a new pyriproxyfen formulation with a potent attractant developed by the manufacturer. Certain studies have reported that Aedes spp. express oviposition behavior for certain types of attractants, such as bamboo leaf infusions [74], octenol [75], and yeast-produced $\mathrm{CO}_{2}$ [76], and these substrates should be considered when MHAQ is used because of their possibility of enhancing the insecticide transference success rate. Furthermore, further investigation on all aspects of the oviposition substrates that act as important oviposition cues should be performed to improve the MHS efficacy before it 
can be considered an alternative tool in vector control management.

\section{Conclusions}

The findings in this study demonstrated that MHS has potential for use as an autodissemination station in future dengue control programs. Most of the parameters tested in our laboratory trials showed encouraging results, despite the formulation of the MHAQ showing a weak attractant effect on the Ae. aegypti. However, small-scale field trials have shown that MHAQ was more attractive than ovitraps, with more eggs collected. Further research should focus on the identification of the compound responsible for attracting Aedes spp. mosquitoes as well as their underlying mechanisms. In addition, it is essential to improve the efficacy of MHS, particularly in semi-field and field conditions, as well as the discovery of new and powerful combinations of MHAQ solutions. The combination of different techniques and approaches may prove to be a powerful alternative tool for vector control programs, particularly in Malaysia.

\section{Abbreviations}

ANOVA: Analysis of varians; El: Emergence inhibition; ER: Effective reduction; HI: Hay infusion; MHAQ: Mosquito Home Aqua; MHS: Mosquito Home System; $\mathrm{RH}$ : Relative humidity; TW: Tap water; WHO: World Health Organization.

\section{Acknowledgements}

We thank the Director General of Health Malaysia for his permission to publish this article. We thank One Team Networks Sdn Bhd, Malaysia, for providing the pyriproxyfen and Mosquito Home System used in this study. We also extend our gratitude to Ms. Rawaida, Ms. Siti Rahayu, and Ms. Hafizah for field sampling. We are grateful to Dr. Vanitha Mariappan and Mr. Steve Page for proofreading of the manuscript.

\section{Authors' contributions}

NWA, HFO, AMMN contributed to the concept and study design. AMMN, NSA, $A A Z$ and $A M L$ performed the experiments and sample collection. $Y L, D G, A M L$ and AMMN analysed the data. HFO, YL, DG, JCSM, MS, RH critically revised and edited the manuscript. AMMN wrote the first draft of the manuscript. HFO, MS and $\mathrm{RH}$ supervised the project. All authors read and approved the final manuscript.

\section{Funding}

This research was funded by Dengue Tech Challenge 2016 Grant, under the Newton-Ungku Omar Fund Partnership (AIM/ PlaTCOM/ HIP2/ CCGF/ 2016/ 088). The grant is funded by the Malaysia Industry-Government Group for High Technology (MIGHT) and the United Kingdom Department for Bussiness, Energy, and Industrial Strategy, delivered by the British Council and PlatCOM Ventures.

\section{Availability of data and materials}

Data supporting the conclusions of this article are included within the article. The datasets used and analyzed during the present study are available from the corresponding author upon reasonable request.

\section{Declarations}

\section{Ethics approval and consent to participate}

No human participants, human data, or human tissue were used in the present study. Insects were fed on guinea pig according to a protocol approved by Research Ethics Committee, The National University of Malaysia (Ref No:
UKMPPI/111/8/JEP-2016-393). This study is registered with the National Medical Research Registered and approved for publication by the Director General of Health, Ministry of Health Malaysia (NMRR ID: NMRR-21-203-58556).

\section{Consent for publication}

Not applicable.

\section{Competing interests}

The authors declare no conflict of interest and the funders had no role in the design of the study; in the collection, analyses, or interpretation of data; in the writing of the manuscript, or in the decision to publish the results.

\section{Author details}

${ }^{1}$ Center for Toxicology and Health Risk, Faculty of Health Sciences, Universiti Kebangsaan Malaysia, 50300 Kuala Lumpur, Federal Territory of Kuala Lumpur, Malaysia. ${ }^{2}$ Medical Entomology Unit, Infectious Disease Research Centre, Institute for Medical Research, National Institute of Health, Ministry of Health, 40170 Shah Alam, Selangor, Malaysia. ${ }^{3}$ Phytochemistry Unit, Herbal Medicine Research Centre (HMRC), Institute for Medical Research, National Institute of Health, Ministry of Health, 40170 Shah Alam, Selangor, Malaysia. ${ }^{4}$ Department of Mathematics and Statistics, University of Strathclyde, Glasgow G1 $1 \mathrm{XH}$, UK. ${ }^{5}$ Department of Biomedical Science, Faculty of Medicine and Health Science, Universiti Putra Malaysia, 43400 Serdang, Selangor, Malaysia. ${ }^{6}$ Department of Community Health, Faculty of Medicine, Universiti Kebangsaan Malaysia, 50600 Cheras, Kuala Lumpur, Malaysia.

Received: 6 October 2020 Accepted: 2 August 2021

Published online: 18 August 2021

\section{References}

1. Chew $\mathrm{CH}$, Woon $\mathrm{YL}$, Amin $\mathrm{F}$, Adnan $\mathrm{TH}$, Wahab AHA, Ahmad ZE, et al. Rural- urban comparison of dengue seroprevalence in Malaysia. BMC Public Health. 2016;16:824.

2. Yusoff HM. National Dengue Programme in Malaysia, In: Asia-Pacific Dengue Program Managers Meeting, Singapore, 5-9 May 2008. World Health Organization -Western Pacific Region; 2008. p. 83-86.

3. Capeding MR, Tran NH, Hadinegoro SRS, Muhamad Ismail HIHJ, Choypitayasunondh T, Chua MN, et al. Clinical efficacy and safety of a novel tetravalent dengue vaccine in healthy children in Asia: aphase 3, randomised, observer-masked, placebo-control trials. Lancet. 2014;384(9951):1358-65.

4. Thomas SJ, Yoon IK. A review of dengvaxia ${ }^{\circledR}$ development to deployment. Hum Vacci Immunother. 2019;15(10):2295-314.

5. Silveira LTC, Tura B, Santos M. Systematic review of dengue vaccine. BMC Infect Dis. 2019;19:750.

6. Robinson ML, Durbin AP. Dengue vaccines: implication for dengue control. Curr Opin Infect Dis. 2017;30(5):449-54.

7. Othman H, Nordin SA, Rashid NA, Abas MBH, Hod R, Sahani M. Dengue free community as an approach for understanding the value and challenges of inter-agencies partnerships in an intervention program. IJPH. 2017:4(6):1810-26.

8. Roiz D, Wilson AL, Scoot TW, Fonseca DM, Jourdain F, Muller F, et al. Integrated Aedes management for the control of Aedes borne diseases. PloS Negl Trop Dis. 2018;12(12):e0006845.

9. Vythilingam I, Wan-Yusoff WS. Dengue vector control in Malaysia: are we moving in the right direction. Trop Biomed. 2017;34(4):746-58.

10. Francis S, Saavedra-Rodriguez K, Perera R, Paine M, Black WC, Delgoda $\mathrm{R}$. Insecticide resistance to permethrin and malathion and associated mechanisms in Aedes aegypti mosquitoes from St. Andrew Jamaica. PLoS ONE. 2017;12(6):e0179673.

11. Goindin D, Delannay C, Gelasse A, Ramdini C, Gaude T, Faucon F, et al. Level of insecticide resistance to deltamethrin, malathion, and temephos, and associated mechanisms in Aedes aegypti mosquitoes from the Guadeloupe and Saint Martin Islands (French West Indies). Infect Dis Poverty. 2017;6:38.

12. Moyes CL, Vontas J, Martins AJ, Ng LC, Koou SY, Dusfour I, et al. Contemporary status of insecticide resistance in the major Aedes vectors of arboviruses infecting humans. PLoS Negl Trop Dis. 2017;11(7):e0005625. 
13. Hidayatulfathi $O$, Shamsuddin $A F$, Rajab NF, NorZafirah AB, Nur Hazwani AA, Nur Afriza MFO, et al. Three repellent gels that contain essential oils from local Malaysian plants against dengue vector. Trop Biomed. 2017;34(3):540-649.

14. World Health Organization. Guidelines for drinking water quality, 3rd edn, including first and second agenda. Geneva: World Health Organization; 2008.

15. Deviller J. Fate of pyriproxyfen in soils and plants. Toxic. 2020;8:20.

16. Santos VSV, Limongi JE, Pereira BB. Association of low concentrations of pyriproxyfen and Spinosad as an environment-friendly strategy to rationalize Aedes aegypti control programs. Chemosphere. 2020;247:125795.

17. WHO. Pyriproxyfen in drinking-water. Background document for development. WHO guidelines for drinking-water quality. Geneva: World Health Organization; 2008. WHO/SDE/WSH/03.04/113.

18. Caputo B, Lenco A, Cianci D, Pombi M, Petrarca V, Baseggio A, et al. The "autodissemination" approach: a novel concept to fight Aedes albopictus in urban areas. PLoS NegI Trop Dis. 2012;6(8):e1793.

19. Devine GJ, Zamora-Perea E, Killeen GF, Stancil JD, Clark SJ, Morrison AC. Using adult mosquitoes to transfer insecticides to Aedes aegypti larval habitats. PNAS. 2009:106(28):11530-4.

20. Suman DS, Wang Y, Faraji A, Williams GM, Williges E, Gaugler R. Seasonal field efficacy of pyriproxyfen autodissemination stations against container-inhabiting mosquito Aedes albopictus under differeny habitat conditions. Pest Manag Sci. 2018;74(4):885-95.

21. Ahmad Mohiddin MN, David G, Asmalia ML, Mazrura S, Rozita H, Hidayatulfathi $O$. A review: autodissemination of pyriproxyfens as novel strategy to control dengue outbreaks. Pertanika J Sci Technol. 2020;28(4):1117-40.

22. Chandel K, Suman DS, Wang Y, Unlu I, Williges E, Williams GM, et al. Targeting a hidden enemy: pyriproxyfen autodissemination strategy for the control of the container mosquito Aedes albopictus in cryptic habitats. PLoS Negl Trop Dis. 2016;10(12):e0005235.

23. Itoh T. Utilization of bloodfed females of Aedes aegypti as a vehicle for the transfer of the insect growth regulator, pyriproxyfen, to larval habitats. Trop Med. 1994;36(4):243-8.

24. Chism BD, Apperson CS. Horizontal transfer of the insect growth regulator pyriproxyfen to larval microcosm by gravid Aedes albopictus and Ochlerotatus triseriatus mosquitoes in the laboratory. Med Vet Entomol. 2003:17(2):211-20.

25. Abad-Franch F, Zamora-Perea E, Ferraz G, Padilla-Torres SD, Luz SLB. Mosquito-disseminated pyriproxyfen yields high breeding-site coverage and boosts juvenile mosquito mortality at the neighborhood scale. PLoS Negl Trop Dis. 2015;9(4):e0003702.

26. Franch AF, Perea EZ, Luz SLB. Mosquito-disseminated insecticide for citywide vector control and its potential to block arbovirus epidemics: entomological observations and modelling results from Amazonian Brazil. Plos Med. 2017;14(1):e1002213.

27. Yazan LS, Paskaran K, Gopalsamy B, Majid RA. Aedestech Mosquito Home System prevents the hatch of Aedes mosquito eggs and reduces its population. Pertanika J Sci Technol. 2020;28(1):263-78.

28. WHO. Monitoring and managing insecticide resistance in Aedes mosquito populations, Interim guidance for entomologists. WHO Department of Control of Neglected Tropical Disease and Global Malaria Programme, Geneva: World Health Organization. 2016. WHO/ZIKVNC/16.1.

29. Ahmad-Azri M, Syamsa RA, Ahmad-Firdaus MS, Aishah-Hani A. A comparison of different types of ovitraps for outdoor monitoring of Aedes mosquitoes in Kuala Lumpur. Trop Biomed. 2019;36(2):335-47.

30. Ali R, Azmi RA, Ahmad NW, Hadi AA, Muhamed KA, Rasli R, et al. Entomological surveillance associated with human zika cases in Miri Sarawak. Malaysia Am J Trop Med Hyg. 2020;102(5):964-70.

31. Sihuincha M, Zamora-Perea E, Orellana-Rios W, Stancil JD, LopezSifuentes $V$, Vidal-Ore C, et al. Potential use of pyriproxyfen for control of Aedes aegypti (Diptera: Culicidae) in lquitos. Peru J Med Entomol. 2005;42(4):620-30.

32. Dieng H, Rajasaygar S, Ahmad AH, Rawi CSM, Ahmad H, Satho T, et al. Indirect effects of cigarette butt waste on the dengue vector Aedes aegypti (Diptera: Culicidae). Acta Trop. 2014;130:123-30.

33. Satho T, Dieng H, Ahmad MHI, Ellias S, AbuHassan A, Abang F, et al. Coffee and its waste repel gravid Aedes albopictus females and inhibit the development of their embryos. Parasit Vectors. 2015;8:272.
34. Zuharah WF, Ahbirami R, Dieng H, Thiagaletchumi M, Fadzly N. Evaluation of sublethal effect of Ipomoea cairica Linn. Extract on life history traits of dengue vectors. Rev Inst Med Trop Sao Paulo. 2016;58:44.

35. Cheong WH, Mahadevan S. Entomological charts for teaching. Division of Medical Entomology, IMR: Kuala Lumpur. 1970.

36. Mishra P, Pandey CM, Singh U, Gupta A, Sahu C, Keshri A. Descriptive statistics and normality tests for statistical data. Ann Card Anaesth. 2019;22(1):67-72.

37. WHO. Efficacy-testing of traps for control of Aedes spp. mosquito vectors Geneva: World Health Organization. 2018. WHO/CDS/NTD/NEM/2019.06.

38. Abbott WS. A method of computing the effectiveness of an insecticide. J Am Mosq Control Assoc. 1925;3:302-3.

39. Fiaz M, Martinez LC, Plata-Rueda A, Gonzalves WG, Souza DLL, Cossolin JFS, et al. Pyriproxyfen, a juvenile hormone analog, damage midgut cells and interferes with behaviors of Aedes aegypti larvae. PeerJ. 2019;7:e7489.

40. Carvalho BL, Germano RNL, Braga KML, Araujo ERF, Rocha DA, Obara MT. Susceptibility of Aedes aegypti populations to pyriproxyfen in the Federal District of Brazil. Rev Soc Bras Med Trop. 2020;53:e20190489.

41. Chen YA, Lai YT, Wu KC, Yen TY, Chen CY, Tsai KH. Using UPLC-MS/MS to evaluate the dissemination of pyriproxyfen by Aedes mosquitoes to combat cryptic larval habitats after source reduction in Kaohsiung in Southern Taiwan. Insect. 2020;11:251.

42. Paul A, Harrington C, Scott JG. Evaluation of novel insecticides for control of dengue vector Aedes aegypti (Diptera: Culicidae). J Med Entomol. 2006;43(1):55-60.

43. Vontas J, Moore S, Immo K, Ranson H, Lindsay S, Lengelar C, et al. Framework for rapid assessment and adoption of new vector control tools. Trends Parasitol. 2014;30(4):191-204.

44. Kawada H, Shono Y, Abe Y. Laboratory evaluation of insect growth regulators against several species of anopheline mosquitoes. Jpn J Sanit Zool. 1993:44(4):349-59.

45. Suman DS, Wang Y, Dong L, Gaugler R. Effects of larval habitat substrate on pyriproxyfen efficacy against Aedes albopictus (Diptera: Culicidae). J Med Entomol. 2013;50(6):1261-6.

46. Lau KW, Chen CD, Lee HL, Norma-Rashid Y, Sofian-Azirun M. Evaluation of insect growth regulators against field-collected Aedes aegypti and Aedes albopictus (Diptera: Culicidae) from Malaysia. J Med Entomol. 2015:52(2):199-206.

47. Harburguer L, Zerba E, Licastro S. Sublethal effect of pyriproxyfen released from a fumigant formulation on fecundity, fertility and ovicidal action in Aedes aegypti (Diptera: Culicidae). J Med Entomol. 2014;51(2):436-43.

48. Devi U, Bora D. Growth inhibitory effect of phenolic extract of Zizphus jujube Mill in dengue vector Aedes aegypti (L.) in parent and F1generation. Asian Pac J Trop Med. 2017;10(8):787-91.

49. Suttana S, Yanola J, Lumjuan N, Somboon P. The efficacy of pyriproxyfentreated resting boxes on the reproductivity of Aedes aegypti (Diptera: Culicidae) in the laboratory. Trop Biomed. 2019:36(2):514-30.

50. Rhyne MN, Richards SL. Impact of the insect growth regulator pyriproxyfen on immature development, fecundity and fertility of Aedes albopictus. J Am Mosq Control Assoc. 2020;36(1):11-5

51. Maoz D, Ward T, Samuel M, Muller P, Runge-Ranzinger S, Toledo J, et al. Community effectiveness of pyriproxyfen as a dengue vector control method: a systematic review. PloS Negl Trop Dis. 2017;11(7):e0005651.

52. Yadav K, Dhiman S, Acharya B, Ghorpade RR, Sukumaran D. Pyriproxyfen treated surface exposure exhibits reproductive disruption in dengue vector Aedes aegypti. PLoS Negl Trop Dis. 2019;13(11):e0007842.

53. Ahmad TH, Saunders TR, Mullins D, Rahman MZ, Zhu J. Molecular action of pyriproxyfen: role of the Methoprene-tolerant protein in the pyriproxyfen-induced sterilization of adult female mosquitoes. PLoS Negl Trop Dis. 2020;14(8):e0008669.

54. Harris C, Lwetoijera DW, Dongus S, Matowo NS, Lorenz LM, Devine GJ, et al. Sterilising effects of pyriproxyfen on Anopheles arabiensis and its potential use in malaria control. Parasit Vectors. 2013;6:144.

55. Ponlawat A, Fansiri T, Kurusarttra S, Pongsiri A, McCardle PW, Evans BP, et al. Development and evaluation of a pyriproxyfen-treated device to control the dengue vector, Aedes aegypti (L.) (Diptera: Culicidae). Southeast Asian J Trop Med Public Health. 2013;44(2):167-78.

56. Silva WA, Silva JS, Ferrerira FAS, Rodrigues IB, Tadei WP, Zequi JAC. Oviposition of Aedes aegypti Linnaeus, 1762 and Aedes albopictus Skuse, 1894 (Diptera: Culicidae) under laboratory and field conditions using ovitraps 
associated to different control agents, Manaus, Amazonas, Brazil. Rev Bras Entomolo. 2018;62(4):304-10.

57. Girard M, Martin E, Vallon L, Raquin V, Bellet C, Rozier Y, et al. Microorganisms associated with mosquito oviposition sites: Implications for habitat selection and insect life histories. Microorganisms. 2021;9:1589.

58. Bennett KL, Martinez CG, Chin Y, Saltonstall K, McMillan WO, Rovira JR, et al. dynamics and diversity of bacteria associated with the disease vectors Aedes aegypti and Aedes albopictus. Sci Rep. 2019;9:12160.

59. Ponnusamy L, Schal C, Wesson DM, Arellano C, Apperson CS. Oviposition responses of Aedes mosquitoes to bacterial isolates from attractive bamboo infusion. Parasit Vectors. 2015;8:486.

60. Seixas G, Paul REL, Pires B, Alves G, Jesus A, Silva AC, et al. An evaluation of efficacy of the autodissemination technique as a tool for Aedes aegypti control in Madeira, Portugal. Parasites Vectors. 2019;12:202.

61. Wong J, Stoddard ST, Astete H, Morrison AM, Scott TW. Oviposition site selection by the dengue vector Aedes aegypti and its implications for dengue control. PLoS Negl Trop Dis. 2011;5(4):e1015.

62. Nazni WA, Bandara MRSS, Azahari AH, Craig RW, Lee HL. Skip oviposition behavior of laboratory, field and transgenic strain of Aedes aegypti (L.). Southeast Asian J Trop Med Public Health. 2016:47(4):680-90.

63. Richards SL, Byrd BD, Reiskind MH, White AV. Assessing insecticide resistance in adult mosquitoes: perspectives on current methods. Environ Health Insight. 2020;14:1-7.

64. Marcombe S, Chonephetsarath S, Thammavong P, Brey PT. Alternative insecticides for larval control of the dengue vector Aedes aegypti in Lao PDR: insecticide resistance and semi-field trial study. Parasites Vectors. 2018;11:616.

65. Brady OJ, Johansson MA, Guera CA, Bhatt S, Golding N, Pigott DM, et al. Modelling adult Aedes aegypti and Aedes albopictus survival at different temperatures in laboratory and field setting. Parasites Vectors. 2013;6:351.

66. Yazan LS, Paskaran K, Gopalsamy B, Majid RA. Aedestech Mosquito Home System prevents the hatch of Aedes mosquito eggs and reduces its population. Pertanika J Sci Technol. 2020;28(1):263-78.

67. Ngesom AMM, Hanif WNW, Lasim AM, Sahani M, Hod R, Othman H. A semi-field and field simulation using autodissemination methods against dengue vector Aedes aegypti (Linnaeus) (Diptera: Culicidae). Serangga. 2020;25(3):12-34.

68. Jiggins FM. The spread of Wolbachia through mosquito populations. PLoS Biol. 2017;15(6):e2002780

69. Unlu I, Suman DS, Wang Y, Klinger K, Faraji A, Gaugler R. Effectiveness of autodissemination stations containing pyriproxyfen in reducing immature Aedes albopictus populations. Parasit Vectors. 2017;10:139.

70. Suman DS, Farajollahi A, Healy S, Williams GM, Wang Y, Schoeler G, et al. Point-source and area-wide field studies of pyriproxyfen autodissemination against urban container-inhabiting mosquitoes. Acta Trop. 2014;135:96-103.

71. Lloyd AM, Farooq M, Estep AS, Xue RD, Kline DL. Evaluation of pyriproxyfen dissemination via Aedes albopictus from a point-source larvicide application in Northeast Florida. J Am Mosq Control Assoc. 2017;33(2):151-5.

72. Swale DR, Li Z, Kraft JZ, Healy K, Liu M, David CM, et al. Development of an autodissemination strategy for the deployment of novel control agents targeting the common malaria mosquito, Anopheles quadrimaculatus say (Diptera: Culicidae). PLoS Negl Trop Dis. 2018;12(4):e0006259.

73. Iyaloo DP, Elahee KB, Bheecarry A, Lees RS. Guidelines to site selection for population surveillance and mosquito control trials: a case study from Mauritius. Acta Trop. 2014;132S:S140-9.

74. Arbaoui AA, Chua TH. Bacteria as a source of oviposition attractant for Aedes aegypti mosquitoes. Trop Biomed. 2014;31(1):134-42.

75. Liu H, Dixon D, Bibbs CS, Xue RD. Autocidal gravid ovitrap incorporation with attractants for control of gravid and host-seeking Aedes aegypti (Diptera: Culicidae). J Med Entomol. 2018;56(2):576-8.

76. Jerry DCT, Mohammed T, Mohammed A. Yeast-generated Co2: A convenient source of carbon dioxide for mosquito trapping using the BG-Sentine $\left.\right|^{\circledR}$ traps. Asian Pacific J Trop Biomed. 2017;7:896-900.

\section{Publisher's Note}

Springer Nature remains neutral with regard to jurisdictional claims in published maps and institutional affiliations.
Ready to submit your research? Choose BMC and benefit from:

- fast, convenient online submission

- thorough peer review by experienced researchers in your field

- rapid publication on acceptance

- support for research data, including large and complex data types

- gold Open Access which fosters wider collaboration and increased citations

- maximum visibility for your research: over 100M website views per year

At BMC, research is always in progress.

Learn more biomedcentral.com/submissions 